\title{
Pelatihan Local Area Network (LAN) dan Access Point Pada SMK Bina Guna Tanah Jawa Kabupaten Simalungun
}

\section{The Training Local Area Network (LAN) And Access Point At SMK Bina Guna Tanah Jawa Kabupaten Simalungun}

\author{
Iin Parlina \& Muhammad Ridwan Lubis
}

Program Studi Komputerisasi Akuntansi AMIK Tunas Bangsa Pematangsiantar

Diterima: Juli 2019 ; Disetujui: Agustus 2019 ; Dipublish: September 2019

*Corresponding Email : $\underline{\text { iin@amiktunasbangsa.ac.id/ridwanlubis@amiktunasbangsa.ac.id }}$

\section{Abstrak}

Dengan Perkembangan teknologi saat ini yang semakin meningkat derastis, sehingga menuntut setiap orang harus paham bagaimana cara memasang jaringan local area network dan cara access point guna untuk sharing data. Dalam hal ini perlu dilakukan pelatihan bagi siswa-siswi SMK yang sedang aktif belajar khususnya bagi jurusan Teknik Jaringan Komputer (TKJ) untuk meningkatkan kemampuan siswa dalam pemasangan jaringan. Karena masih banyak siswa yang tidak mengerti tentang jaringan. Sehingga pelatihan ini sangat perlu dilakukan, dan persiapan siswa siswi pun semakin matang dalam menghadapi ujian kompetensi dikemudian harinya.

Kata Kunci : Local Area Network, Access Point dan siswa

\section{Abstract}

With the development of current technology that is increasing drastically, so it requires everyone to understand how to install a local area network and how to access points to share data. In this case it is necessary to do training for Vocational students who are actively studying especially for Computer Network Engineering (CNE) majors to improve students' abilities in network installation. Because there are still many students who do not understand about networks. So that this training is very necessary, and the preparation of female students is even more mature in facing the competency exam in the future.

Keywords: Local Area Network, Access Point and students

How to cite : Parlina, I. \& Lubis M,R. (2019). Pelatihan Local Area Network (LAN) dan Access Point Pada SMK Bina Guna Tanah Jawa Kabupaten Simalungun. Pelita Masyarakat : Jurnal Pengabdian Masyarakat 1(1) :16-23 


\section{PENDAHULUAN}

Pengetahuan akan teknologi informasi sudah menjadi kebutuhan yang wajib dipenuhi seseorang. Hal tersebut dikarenakan hampir sebagian besar kegiatan seharihari seseorang melibatkan bantuan teknologi baik kegiatan belajar mengajar, bekerja di Perusahaan maupun berwirausaha. Selain itu juga pengetahuan akan teknologi merupakan modal utama seseorang untuk dapat bersaing di era globalisasi dan kemajuan zaman yang akan datang. Ilmu komputer merupakan salah satu teknologi yang banyak diterapkan dalam dunia kerja dan wirausaha. Hal ini dikarenakan komputer dapat digunakan untuk mempermudah dan mengurangi tingkat kesulitan dalam bekerja maupun berwirausaha.

Siswa-siswi SMK Bina Guna Tanah Jawa salah satu sekolah yang siswa-siswinya kurang memahami pengetahuan mengenai ilmu teknologi komputer jaringan, khususnya pada bidang Jaringan. Kemampuan siswa siswi dalam memperaktekkan jaringan tersebut sangatlah kurang, sehingga dapat diketahui bahwa siswa yang memiliki skill tentang jaringan hanya 2 orang siswa itupun proses kerjanya sangat lambat, sedangkan sisanya ada 38 siswa/I tidak bisa sama sekali memasang jaringan secara otodidak. Hal inilah yang mendorong tim Pengabdian Kepada Masyarakat untuk perlu melakukan pelatihan terhadap siswa/I SMK Bina Guna Tanah Jawa Kabupaten Simalungun Untuk menyalurkan ilmunya sebagai upaya pengabdian kepada masyarakat guna membekali ilmu berupa skill yang dapat menunjang kemampuan siswa sehingga mempunyai keahlian dalam jaringan komputer dan bisa bersaing di dunia kerja. Salah satu upaya yang dapat dilakukan yaitu dengan memberikan pelatihan dasar jaringan.

\section{ANALISIS SITUASIONAL}

SMK Bina Guna Tanah Jawa, beralamatkan di Balimbingan, Tanah Jawa, Kabupaten Simalungun, Sumatera Utara 21181. SMK Bina Guna Tanah Jawa berstatus swasta, bentuk pendidikan SMK, status kepemilikan Yayasan, Luas Tanah 3675 tanggal SK pendirian 6 September 2010, dengan SK Izin Operasional 188.420/4320/MN/Disdik/2015 serta tanggal SK Izin Operasional : 21 Desember 2015 Sejak berdirinya di Propinsi Sumatera Utara. 
SMK Bina Guna Tanah Jawa yang telah terdaftar dan Ter Akreditasi B di Kabupaten Simalungun khususnya di Tanah Jawa Kabupaten Simalungun atas dasar Visi, Misi dan Tujuan Sekolah, serta penggalangan SMK Kejuruan oleh Pemerintah maka Sampe Tua Sihotang, SE, S.Pd. selaku pendiri, memberikan jalan kepada masyarakat setempat untuk generasi muda agar melanjutkan sekolah ke tingkat SMK Sederajat, khususnya di lingkungan Tanah Jawa. SMK Bina Guna Tanah Jawa merupakan pusat pendidikan yang mementingkan sosial masyarakat disamping mempertahankan kualitas Yayasan SMK Bina Guna Tanah Jawa dengan latar belakang pendidikan yang sesuai aturan dan diakui.

Komponen dan Kontribusi yang diperoleh dan dibutuhkan siswa, salah satunya adalah skill. Salah satu kemampuan siswa dalam pemasangan jaringan adalah didukungnya peralatan dan media yang paling utama seperti perangkat-perangkat yang berkaitan dengan pemasangan jaringan yautu Kabel, RG, Tester Kabel RJ45, Tang penjepit, gunting, komputer server, komputer user, dan Printer. jaringan komputer saat ini adalah dimanfaatkan para pelajar untuk mengkoneksikan internet. Pemasangan jaringan LAN yang dilakukan para siswa dianggap sangat berpengaruh terhadap pembentukan karakter ataupun skill. Ilmu tentang Teknik Jaringan Komputer ini memberikan pengetahuan dan pengalaman yang berharga dan pada akhirnya dapat membentuk skill siswa. Dan skill ini dapat dipergunakan siswa untuk mengembangkan kemampuan khususnya pada bisnis wiraswasta sebagai teknisi jaringan komputer[9].

\section{METODE PELAKSANAAN}

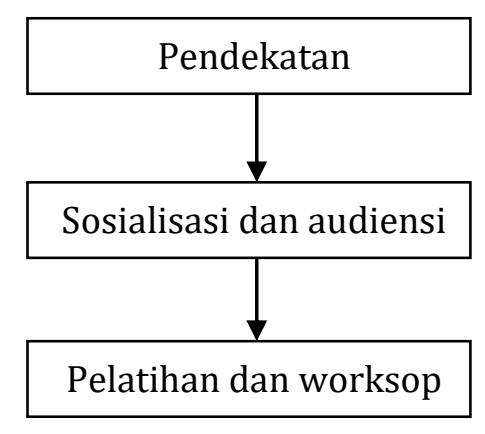

a. Tahap Pendekatan

Dengan Menghubungi kepala sekolah SMK Bina Guna Tanah Jawa Kabupaten Simalungun Menjelaskan latar belakang dan tujuan program yang akan diterapkan dan memberikan motivasi kepada guru-guru di sekolah SMK Bina Guna Tanah 
Jawa Kabupaten Simalungun agar program ini dirasakan sebagai kebutuhan untuk mereka jalankan.

Caranya dengan mengumpulkan siswa/siswi tersebut dan berdiskusi bersama dengan mempersiapkan surat izin dengan mitra, mempersiapkan tempat pelatihan, mempersiapkan alat dan bahan.

b. Tahap sosialisasi dan audiensi

Sosialisasi mengenai pelatihan dan workshop tentang bagaimana mengkoneksikan Jaringan Internet secara nirkabel LAN dan Access Point dengan baik di SMK Bina Guna Tanah Jawa Kabupaten Simalungun.

c. Tahap pelatihan dan workshop

Tentang bagaimana mengkoneksikan Jaringan Internet secara nirkabel LAN dan Access Point dengan baik di SMK Bina Guna Tanah Jawa Kabupaten Simalungun bagi siswa siswi. Mempersiapkan bahan dan alat yang dibutuhkan, kemudian mempraktekkan langsung dan memberikan pelatihan yang diikuti oleh siswa/siswi di SMK Bina Guna Tanah Jawa secara langsung secara bertahap.

\section{HASIL DAN PEMBAHASAN}

Sosialisasi untuk siswa pada kelas ini diberikan dengan menjelaskan seputar lingkup ilmu komputer yang akan menjadi bahan bagi mereka untuk bisa diterapkan dengan ilmu yang saat ini dipelajari pada tingkatan SMK. Hal-hal yang diberikan pada sosialisasi ini adalah tentang pelatihan bagaimana cara merakit kabel LAN, mengkoneksi LAN dan Access point menggunakan wifi dan bagaimana cara sharing data. Pemaparan materi ini cukup membuat mereka fokus dengan worksop pelatihan yang disampaikan. Materi dijelaskan dengan rangkaian penjelasan mengenai jaringan dan Materi tersebut langsung dipraktekkan oleh siswa siswi dengan seksama dan dipandu oleh tim pelatihan tersebut. Sesi pemaparan dilanjutkan dengan sesi tanya jawab. Siswa SMK diberikan kesempatan untuk mengajukan pertanyaan dan dijawab langsung oleh promoter worksop pelatihan yang berlangsung. Siswa SMK Bina Guna tampak cukup tertarik dengan pelatihan ini. Hal ini dapat terlihat pada situasi pelatihan secara langsung yang 
diperaktekkan di dalam lab jaringan. Sesi sosialisasi ditutup dengan kata sambutan dan ucapan terimakasi kepada pihak kepala sekolah.

Kegiatan sosialisasi ini diharapkan dapat memberikan manfaat bagi para pelajar, khususnya siswa SMK Bina Guna peserta kegiatan sosialisasi. Manfaat dari pelatihan ini antara lain melatih siswa siswi yang tidak paham tentang jaringan, dan accesss point menjadi paham dan langsung dapat mengimplementasikan, dengan askill yang dimiliki siswa siswi ini sebagai motivasi untuk melanjutkan ke jenjang pendidikan yang lebih tinggi lagi setelah lulus sekolah. Kegiatan ini juga diharapkan dapat dilakukan sebagai kegiatan reguler sebagai bentuk interaksi antar lembaga di dunia pendidikan

Dokumentasi kegiatan sosialisasi teknologi informasi dapat dilihat pada gambar 2-5 berikut ini:

Evaluasi kegiatan berupa mengerjakan dan memperaktikkan secara langsung menggunakan alat-alat yang disediakan seperti nirkabel, komputer PC ataupun Laptop, 1 Unit Komputer untuk Server, printer, dll untuk mengkoneksikan jaringan internet tersebut dengan baik

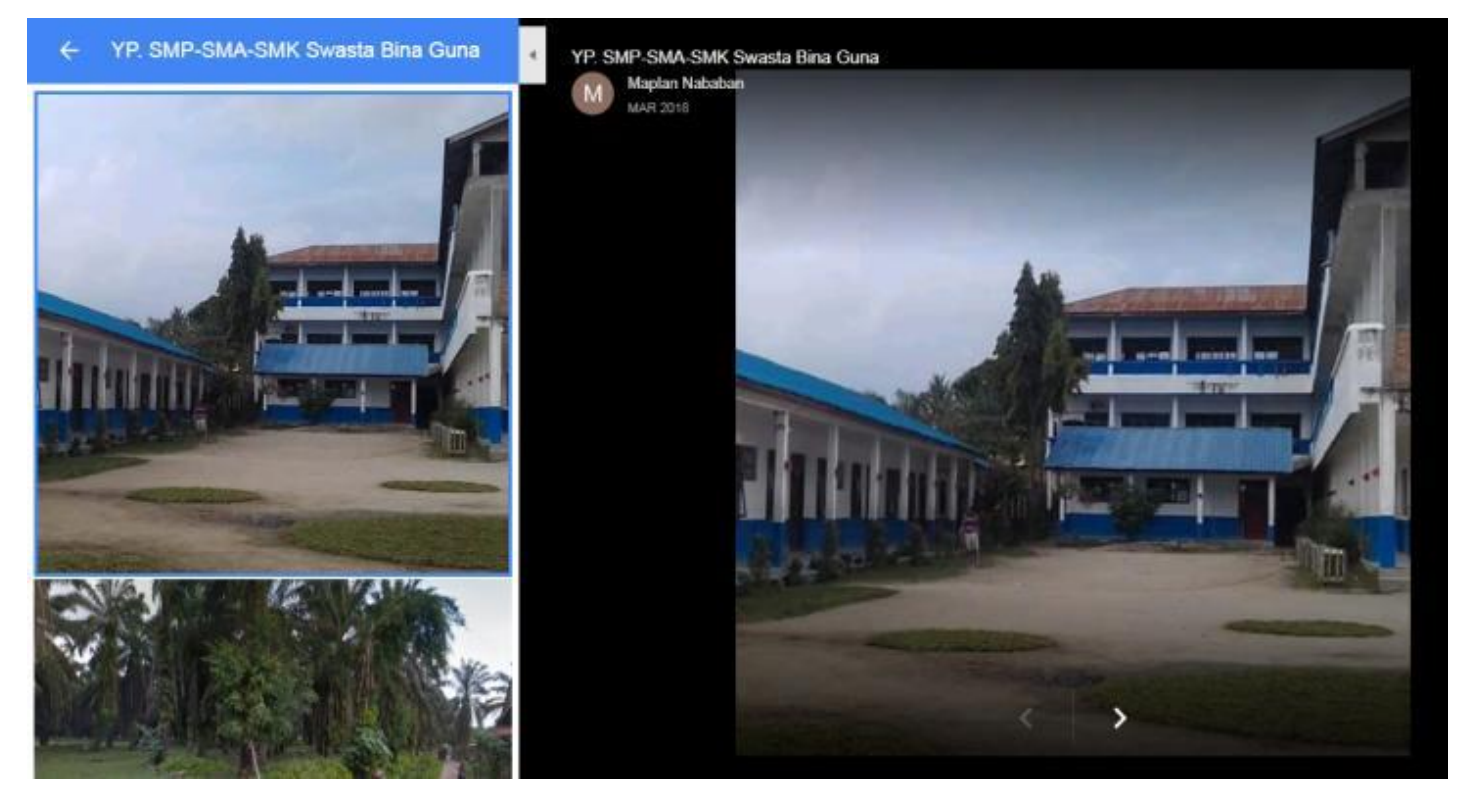

Gambar 1. Halaman Gedung SMK Bina Guna Tanah Jawa

Kabupaten Simalungun 


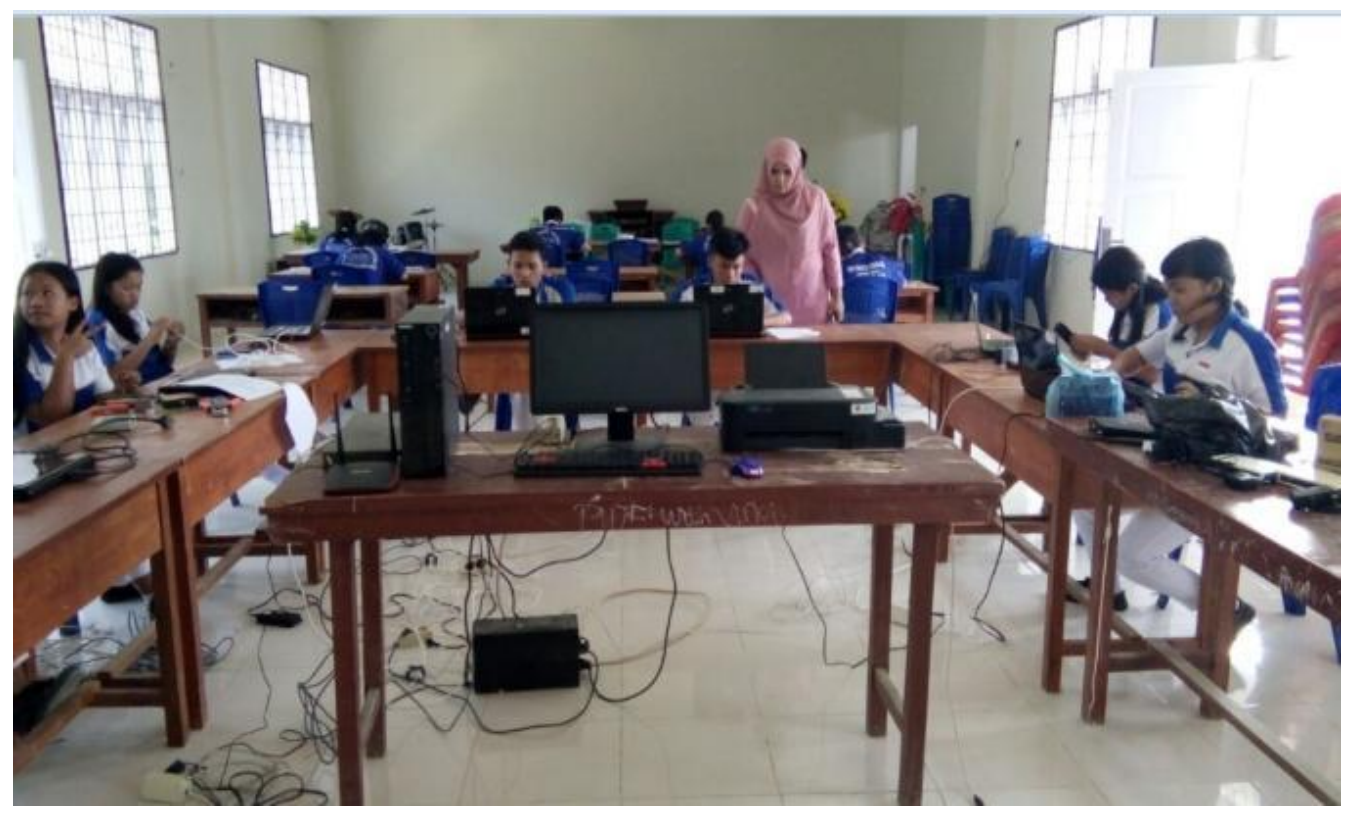

Gambar 2. Suasana Pelatihan hari ke-1pada Siswa/i SMK Bina Guna

Tanah Jawa Kab.Simalungun

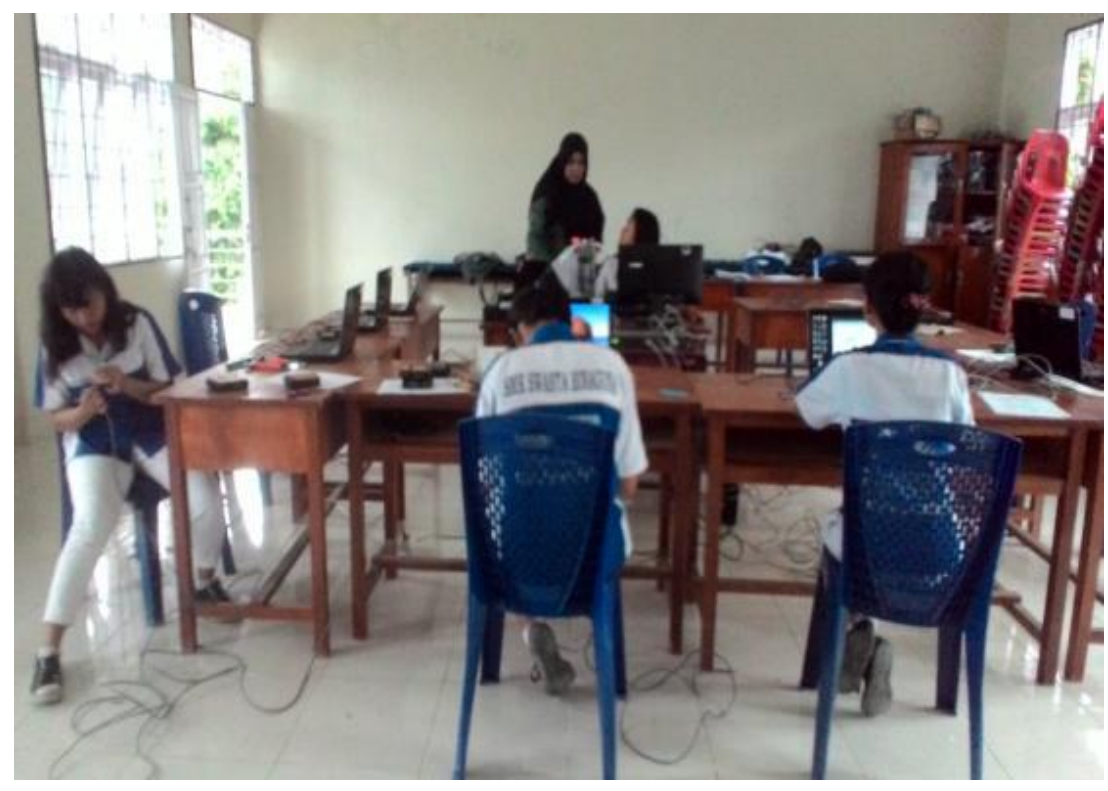

Gambar 3. Suasana Pelatihan hari ke-2 dan Siswa/i sedang Bertanya pada saat melakukan pelatihan 


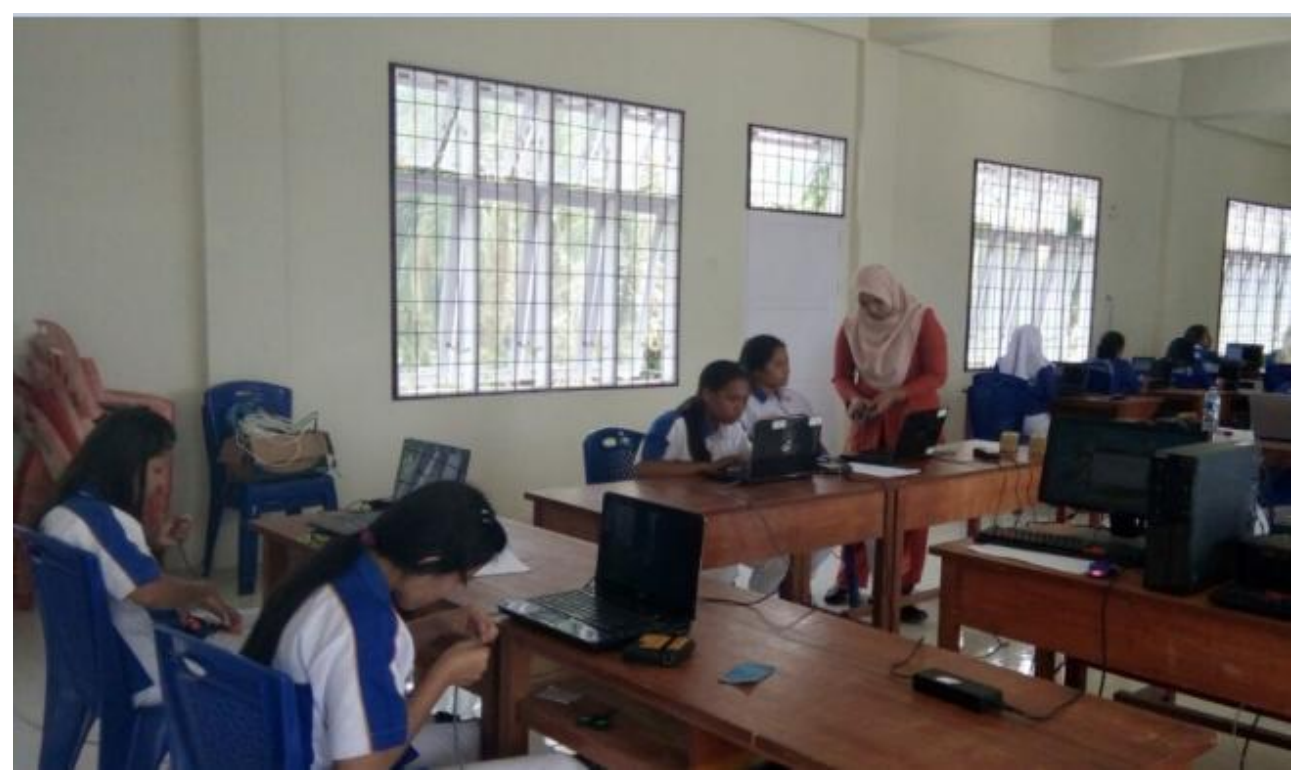

Gambar 4. Suasana Pelatihan hari ke-3 pada Siswa/i SMK Bina Guna Tanah Jawa Kab.Simalungun

Salah satu tujuan dari kegiatan pengabdian ini adalah untuk meningkatkan kemampuan siswa/I SMK Bina Guna Tanah Jawa dan untuk membekali skill kususnya pada mata pelajaran ilmu komputer seperti Teknik Jaringan Komputer.

\section{SIMPULAN}

Berdasarkan tahapan kegiatan yang telah dilakukan dan hasil yang diperoleh, yaitu kegiatan pengabdian yang dilakukan memiliki dampak pada siswa/I SMK Bina Guna Tanah Jawa. Dimana siswa/I memiliki kemampuan untuk membuat access point pada sebuah jaringan Komputer. Siswa/I dapat memasang jaringan secara individu. Kegiatan pengabdian ini dilakukan secara perencanaan

\section{UCAPAN TERIMAKASIH}

Kegiatan pengabdian ini merupakan bagian dari kegiatan IPTEKS bagi Masyarakat yang dibiayai oleh Yayasan AMIK Tunas Bangsa melalui Lembaga Pengabdian Masyarakat. Ucapan terima kasih disampaikan penulis kepada Yayasan AMIK Tunas Bangsa dan Lembaga Penelitian dan Pengabdian Masyarakat AMIK Tunas Bangsa Pematangsiantar yang telah membiayai kegiatan pengabdian ini. 
Syafrizal, M. (2005) Pengantar jaringan komputer. Penerbit Andi,

Utomo, A,P. (2014): "Pemodelan arsitektur enterprise sistem informasi akademik pada perguruan tinggi menggunakan enterprise architecture planning." Simetris: Jurnal Teknik Mesin, Elektro dan Ilmu Komputer 5.1 33-40.

Pradikta, R, Affandi, A., \& Setijadi, E. (2013). Rancang Bangun Aplikasi Monitoring Jaringan dengan Menggunakan Simple Network Management Protocol. Jurnal Teknik ITS, 2(1), A154-A159.

Mayeni, M. (2017): "Sosialisasi Teknologi Informasi: Pengabdian Masyarakat pada Siswa SMK Taruna Bhakti Depok." JATI EMAS (Jurnal Aplikasi Teknik dan Pengabdian Masyarakat) 1.1 21-25. 